\title{
Cascaded Feed Forward Multilayer Neural Network based MPPT Controller for Improving the Performance of Photovoltaic System
}

\author{
Mr. M Rupesh ${ }^{1}$, Dr. T S Vishwanath ${ }^{2}$, Dr. M Venkatesh Kumar ${ }^{3}$ \\ ${ }^{1}$ Research Scholar, EE VTU, Belagam, Karnataka, India, and Assistant Professor, Department of EEE, BVRIT \\ HYDERABAD College of Engineering for Women, Hyderabad, India. \\ ${ }^{2}$ Professor, Department of ECE, Bheemanna Khandre Institute of Technology, Bhalki, Karnataka, India, \\ ${ }^{3}$ Assistant Professor (Sr. G), Amrita School of Engineering, Amrita Vishwa Vidyapeetham, Chennai
}

Article History: Received: 11 January 2021; Revised: 12 February 2021; Accepted: 27 March 2021; Published online: 28 April 2021

\begin{abstract}
This paper deals with the energy production of photovoltaic (PV) cells in different weather conditions. Today, photovoltaic generation plays an important role in generating electricity and satisfies the demand of the island's consumers. The power generation of the PV cell was completely dependent upon sunlight and temperature, but sunlight and temperature changed forever in nature. The many researchers are working on different MPPT technologies for a PV system. Conventional MPPT controllers cannot withstand a sudden change of weather conditions. The main aim of this article is to compare the various conventional and intelligent controller such as the GA, Fuzzy, KGMO, and CNFF for MPPT of the PV system. The proposed intelligent controller was developed and simulated by the MATLAB environment for MPPT in the PV system. In addition, the above results are evaluated and compared. Based on performance, the optimal smart controller has been recommended as MPPT of the PV system.
\end{abstract}

Keywords: Cascaded Feed Forwarded Neural Network (CFNN), KGMO, Fuzzy, GA, MPPT, PV

\section{INTRODUCTION}

The quick growth in energy consumption, $\mathrm{CO} 2$ emissions and the global inadequacy of demand and supply is due to the increasing rate of population growth and levels of urbanization [1][2]. Under the environmental concern like shortage of energy and pollution, RES such as Solar and Wind are the most suitable replaced energy sources which are presence the foremost energy of recent power systems. Micro grid (MG) integrates flexible DGs, such as wind power, solar power and fuel cells, with manageable storage and loads to form a low-voltage distribution system [3-6]. They improve the reliability of the network and provide durability and quality electrical energy. Managing an MG with an extensive selection of Distributing Generations, fluctuating loads and ESA is a difficult task, particularly below the high level of penetration of renewable energy (RG) generation. The RG is typically organized using maximum power tracking algorithms to emphasize the high use of efficiency energy [7-10]. It is therefore considered a generation that cannot be modulated because of changing and uncontrollable weather conditions [11-15]. Maximum power monitoring technology will play a major role in producing maximum energy from a photovoltaic cell in various weather conditions. A major challenge to regulate the PV generated non-linear current characteristics and voltage during periods of low sunshine or partially shaded situations. Many MPPT algorithms have now been proposed by the researchers to achieve maximum energy production from a photovoltaic system.

Among many little MPPT techniques are very popular like P\&O, Incremental Conditions, Feedback voltage and current, voltage and frequency method, feedback power methods. The above conventional methods fail to achieve the speed of operation and maximum power production due to lack of self-regulation capability. In this document proposed various intelligent controller based on MPPT techniques to achieve maximum power output as well as operating speed (auto-adjustment). MPPT techniques based on intelligence are modelled and analyzed in the MATLAB environment. Section 2 provides the mathematical model for the photovoltaic system and design of boost converter. The various Smart Controllers are addressed in Section 3. The proposed intelligent controllers are modelled in Section 4 intelligent Controllers are simulated in MATLAB and analyzed the performances of PV system with various weather conditions. Finally, the hardware and comparative study is presented in section 5. Conclusion of the proposed research is delivered in Section 6.

\section{MPPT SYSTEM}

RGs plays a vibrant role in reaching consumer's energy requirement because of their ampleness and lower environmental influence. The key obstacle to expanding PV power is the capital cost of implementing the PV system [8]. The production of energy through PV is not constant throughout the day because of climate change. The productivity of electricity production is very low (the productivity is in between 10-17\% in low radiation regions). 
Consequently, MPPT technologies play a vibrant role in the production of PV energy for best energy production in various environmental circumstances. Various MPPT methodologies are discussed below.

\section{II.I Mathematical Model of Photovoltaic System}

The photovoltaic cell is depicted as a Dependent current source parallel to a diode as shown in the Figure 1 including supplementary series and parallel resistors. It should be noted that there will be no power generation in the absence of solar light and that the PV cell will act as a diode. True current from the current source (PV cell) depends on the daylight effectively falling on the PV cell (photo-current) (Figure 1)



Open Circuit Voltage

Fig.1. The Equivalent PV cell Circuit

The PV cell voltage production be subject to the voltage drop across the diode,

$$
\mathrm{V}=\left(\frac{\mathrm{NKT}}{\mathrm{Q}}\right) \ln \frac{\mathrm{I}_{\mathrm{L}}-\mathrm{I}_{\mathrm{O}}}{\mathrm{I}_{\mathrm{o}}}+1
$$

Where

$\mathrm{V}=\mathrm{PV}$ Cell OC voltage

$\mathrm{N}=$ diode constant 1.50

$\mathrm{K}=$ Boltz const $(1.381 \times 10-23 \mathrm{JK}-1)$

$\mathrm{T}=$ temp in Kelvin

$\mathrm{Q}=$ elementary charge (1.602 $\times 10-19$ Coulomb)

$\mathrm{IL}=$ current generated by the light $=\mathrm{Iph}(\mathrm{A})$

Io $=$ diode current capacity (A)

Current Generated by the Light (Radiation)

Where

$$
\mathrm{I}_{\mathrm{L}}=\left(\frac{\mathrm{G}}{\mathrm{G}_{\mathrm{ref}}}\right) *\left(\mathrm{I}_{\mathrm{L} \text { ref }}+\propto_{I s C}\left(\mathrm{~T}_{\mathrm{C}}-\mathrm{T}_{\mathrm{C} \text { ref }}\right)\right)
$$

$\mathrm{G}=$ instant irradiation $(\mathrm{W} / \mathrm{m} 2)$

Gref $=$ reference irradiation under standard condition $1000 \mathrm{~W} / \mathrm{m} 2$

ILref $=$ reference Photoelectric current under standard condition $0.15 \mathrm{~A}$

$\mathrm{Tc}=$ Instant temp.

TCref $=$ temp of the model at $298.0 \mathrm{~K}$

$\alpha \mathrm{ISC}=$ short circuit current temp co-effi $(\mathrm{A} / \mathrm{K})=0.0065 \mathrm{AK}-1$

IL is Current Generated by the Light (Radiation)

Reverse Current Capacity

$$
\begin{aligned}
& \text { Io }=I_{\text {or }}\left(\frac{\mathrm{T}_{\mathrm{C}}}{\mathrm{T}_{\text {ref }}}\right)^{3} \mathrm{e}^{\left.\frac{(\mathrm{Q} * \mathrm{Eg})}{(\mathrm{K} * \mathrm{~N}) *\left(\frac{1}{\mathrm{Tcref}}\right)-\left(\frac{1}{\mathrm{Tc}}\right)}\right)} \\
& \mathbf{I}_{\text {or }}=\frac{\mathbf{I}_{\text {scn }}}{\mathbf{e}^{\left(\frac{\mathbf{V}_{\text {ocn }}}{\mathrm{N} * \mathrm{~V}_{\text {tr }}}\right)}}
\end{aligned}
$$

Where

Io $=$ Reverse current Capacity

Ior $=$ current Capacity

$\mathrm{Eg}=$ silicon diode band gap $1.10 \mathrm{eV}$

$\mathrm{S} \mathrm{C}$ Current $(\mathrm{Ish}=\mathrm{Il})$

This is the utmost value of the current produced by a cell under SC conditions: Volt $=0.00 \mathrm{~V}$

$$
\mathbf{I}_{\mathbf{s h}}=\left(\mathbf{I}_{\mathbf{L}}-\mathbf{I}_{\mathbf{o}}\right) *\left(\mathbf{e}^{\frac{\mathrm{eV}}{\mathrm{KT}}}-\mathbf{1}\right) \mathbf{A}
$$




\section{II.II. Boost Converter Design.}

Boost Converter is working as a DC-DC step up converter, which is used to convert fluctuating DC voltage with respect to change in weather conditions to constant stepped up voltage to connect to the inverter for grid integration and domestic applications, here the boost converter is designed with diode, MOSFET as switch and load element to capture the output voltage. The output voltage is varied according to triggering duty cycle. Fig. 2 shows the basic structure of boost converter.

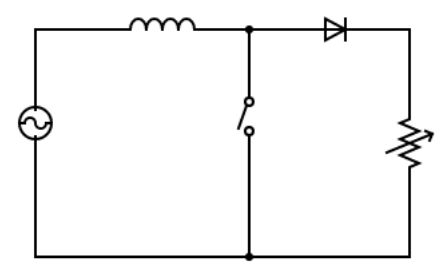

Duty cycle of MOSFET or switch is given as

Fig.2. Basic Structure of Boost Converter

$$
D=\left[1-\frac{V_{\text {in }(\min ) * \eta}}{V_{\text {out }}}\right]
$$

Change in ripple current

$$
d i=i_{\text {ripple }} * i_{\text {out }} * \frac{v_{\text {out }}}{v_{\text {in }}}
$$

The output current of converter

$$
I_{\text {out }}=\frac{\text { Converter Power Rating }}{\text { Converter output voltage }}
$$

Inductance of boost converter

$$
L=\frac{\left[v_{\text {in }}\left(v_{\text {out }}-v_{\text {in }}\right)\right]}{d i * f_{s} * v_{\text {out }}}
$$

Acceptable change in voltage

$$
D v=\frac{v_{\text {out }}}{\text { dv percent } / 100}
$$

Output capacitor to reduce the ripples

$$
C=\frac{I_{o u t} * D}{f_{s} * d v}
$$

Output Resistor

$$
R=\frac{V_{\text {out }}}{I_{\text {out }}}
$$

\section{MPPT ALGORITHMS}

\section{III.I. Fuzzy Logic (FL) Controller Algorithm}

The FL controller is the most popular expert systems and proven intelligent algorithm. The basic fuzzy control block diagram is shown in fig.3.a the fuzzy logic supervisor has two inputs such as a modification in voltage and modification in power as shown in fig 3.b. The output of fuzzy logic supervisor is the duty cycle of semiconductor switch (MOSFET). The input membership function of FL controller has 5 major subdivision, such as NB, NS, Z, PS and $\mathrm{PB}$ as shown in fig 3.c \& fig 3.d. In this input membership function trapezoidal function has been used for negative big and positive big for smoothing the operation. Other membership functions are a triangular function has been used for other membership functions such as negative small, zero and positive small [8]. Based on input and output membership function the fuzzy rules-based inference system has been developed 25 rules presented in fig 3.e. 


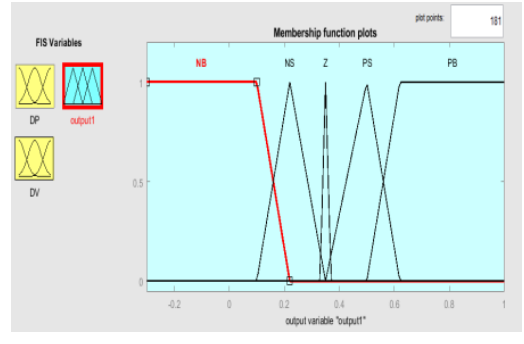

(b)

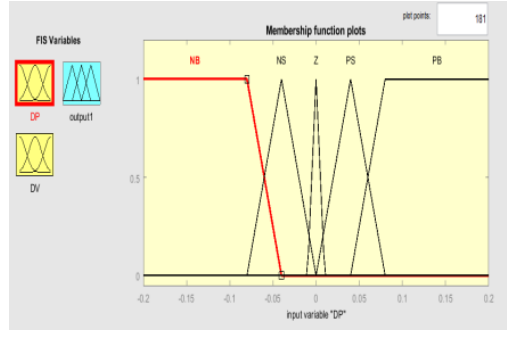

(c)

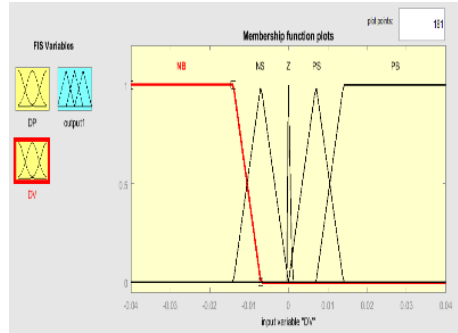

(d)

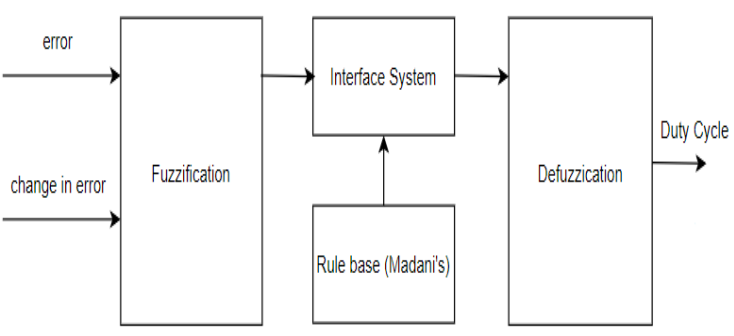

(a)


(e)

Fig.3. Fuzzy Logic Controller design parameters

(a). Basic block diagram of Fuzzy Controller (b). Fuzzy input membership function of change in power to change in voltage (c). Fuzzy input membership function of rate of change in power to rate of change in voltage (d). Fuzzy output membership function of duty cycle. (e). Fuzzy rules-based inference system

\section{III.II. Genetic Algorithm}

Table 1. Fuzzy Rules

\begin{tabular}{|c|l|l|l|l|l|}
\hline $\begin{array}{c}\text { DP/DV/ } \\
\text { Change in DP/DV }\end{array}$ & NB & NS & $\mathbf{Z}$ & PS & PB \\
\hline NB & PB & PS & NB & NS & NS \\
\hline NS & PS & PS & NB & NS & NS \\
\hline Z & NS & NS & NS & PB & PB \\
\hline PS & NS & PB & PS & NB & PB \\
\hline PB & NB & NB & PB & PS & PB \\
\hline
\end{tabular}

GA is an algorithm for stochastic optimization through natural genetic selection. The process takes OC Voltage and Isaac as contributions and it results the best maximum power current (Imp) using the modelling of the cell, without knowledge of the ordinance and temperature [16-18]. The process is developed using MATLAB Code in the embedded Simulink block by the essential functions, with the Genetic Algorithm constraints and PV constraints are respectively the parameters Genetic Algorithm and PV panel. The fig.4 shows the flowchart of Genetic algorithm.

\section{III.III. KGMO Algorithm}

The basic principle of gas molecules optimization algorithm (KGMO) was suggested with the concept of laws of gas molecules. It develops laws based on experiential explanations to convey the macroscopic performance of gas particles. The nuclear theory of gases tells that all materials consist of a great number of molecules or atoms. The properties of gases like pressure, volume and temperature are the outcomes of the achievement of the particles that comprise the gas. There are five theories that define how molecules perform in a gas. The molecular kinetic concept of 
idyllic gases is described as follows:

1. A gas consists of a group of particles that transportable in a conventional, Motion of gas particles based upon the Newton's law.

2. Particles within a gas are sockets and do not inhabit any volume.

3. The Bump of particles are totally flexible hence no energy is increased nor vanished over the course of the Bump.

4. There are no alluring or repulsive forces exist among the particles.

5. The avg KE of a particle is 3 , it is $=2$, when $\mathrm{T}$ is the out-and-out temp, and $\mathrm{k}$ is Boltz const.

$$
\begin{aligned}
& X_{i=x_{i}^{1}, \ldots, x_{i}^{d}, \ldots, x_{i}^{n}} \\
& V_{i=v_{i}^{1}, \ldots, v_{i}^{d}, \ldots, v_{i}^{n}} \\
& K_{i}^{d}(t)=\frac{3}{2} N b T_{i}^{d}(t), K_{i=N_{p}} \\
& \left.V_{i}^{d}(t+1)=T_{i}^{d}(t) w v_{i}^{d}(t)+C_{1} \operatorname{rand}_{i}^{d}(t)\left(\text { gbest }^{d}-x_{i}^{d}(t)\right)+C_{2} \operatorname{rand}_{i}(t) \text { pbest }_{i}^{d}(t)-x_{i}^{d}(t)\right) \\
& T_{i}^{d}(t)=0.95 \times T_{i}^{d}(t-1) \\
& X_{i}^{d}(t+1)=\frac{1}{2} a_{i}^{d}(t+1) \times t^{2}+V_{i}^{d}(t+1) \times t+x_{i}^{d}(t)
\end{aligned}
$$

This segment outlines the kinetic optimization development with gas molecules. The gas particles moves with in the vessel till they meet into the part of vessel which has the least temp and KE. Gas particles interest each other on the basis of low intermolecular electric forces, where the electric force is the outcome of progressive and adverse loads in the particles. In this method, each gas particle and the agent, has four features: position, KE, speed \& mass. The kinetics of every gas particle determine the speed and location of the gas molecule. In this method, the gas particles discover the whole research space and achieve the lowest temp. The fig.5. Shows the flow chart of KGMO algorithm

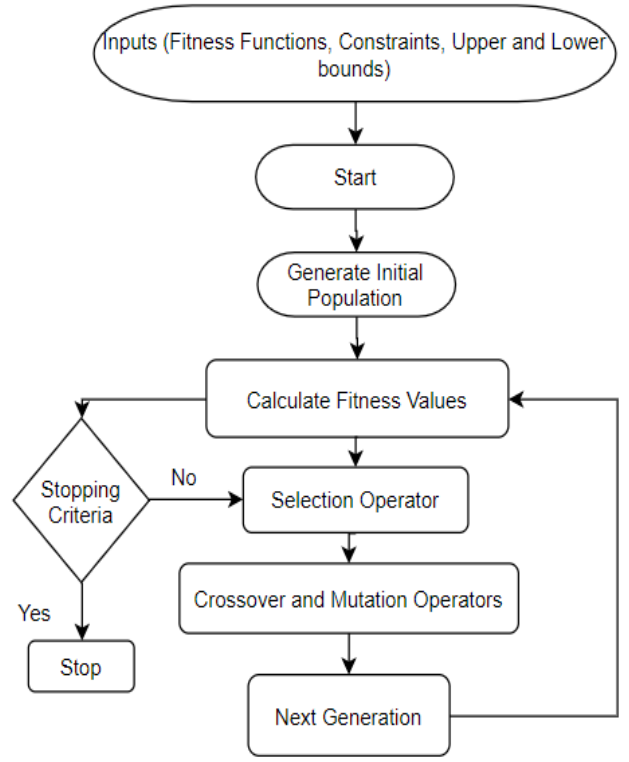

Fig.4. Flowchart for Genetic Algorithm



Fig.5. Flowchart for KGMO Algorithm

\section{III.IV. Cascaded Feed Forward Neural Network (CFNN) (Machine Learning based) MPPT Algorithm}

The CFNN is a feed-forward (FF) neural network, $s$ but it includes a link from the contribution layer and each prior layer to the following layers. In a three-layer network, the production layer is also associated openly to the contribution layer adjacent to the concealed layer. As with FF networks, a cascading network with 2 or more layers 
may learn any arbitrarily finite I-O relationship with enough hidden neurons [19-22]. The CFNN can be used for any type of contribution to the production cartography.

The benefit of this technique is that it takes into account the non-linear association among entry and exit without eradicating the linear affiliation between the two.

In the perceptron assembly which is designed among the contribution and the production is a form of undeviating association, whereas on FFNN the assembly formed among the contribution and the production is a secondary association. The linking is non-linear by an activating function in the concealed layer. If the linking form on perceptron and multilayer grid is combined, then the grid with a direct linking among the contribution layer and the production layer is molded, moreover the linking incidentally. The network formed from this connecting model is known as the CFNN. be as follows:

The network molded by this linking model is named a cascading neural network (CFNN). The equations can

$$
y=\sum_{i=1}^{n} f^{i} w_{i}^{i} x_{i}+f^{o}\left(\sum_{j=1}^{k} w_{j}^{o} f_{j}^{h}\left(\sum_{i=1}^{n} w_{j i}^{h} x_{i}\right)\right)
$$

Where fi is the activation function and wii is weight from the contribution layer to the production layer. If a bias is introduced to the contribution layer and the activation function of each neuron in the concealed layer is fh then equation becomes

$$
y=\sum_{i=1}^{n} f^{i} w_{i}^{i} x_{i}+f^{o}\left(w^{b}+\sum_{j=1}^{k} w_{j}^{o} f_{j}^{h}\left(w^{b}+\sum_{i=1}^{n} w_{j i}^{h} x_{i}\right)\right)
$$

In this investigation, the CFNN model is applied in time series data. Thus, the neurons in the contribution layer are the lags of time series data Xt-1, Xt-2, .., Xt-p, whereas the production is the current data Xt.

The proposed multi-layered cascade neural network model has been developed for an algorithm to trace maximum power points for the PV system as shown in fig 6.a.. This network is equipped with two contributions such as PV voltage and PV current. The production of this network is the duty cycle of DC-DC converter. There are 4 concealed layers used from the contribution layer to the production layer. Each concealed layer has a different number of neural are used such as 20 neurons are used in layer 1,30 neurons are used in layer 2, 20 neurons are used in layer 3 and 5 neurons are used in layer as shown in fig. The proposed network has been trained on more than 10000 data such as PV voltage, PV current and duty cycle. The more than 1000 epochs have been done to generate the MPPT algorithm and this network has been well trained. Thus, the best driving performance of the proposed CNFF is $9.2922 \times 16-17$, as shown in the fig 6.b.. Gradient analysis, Mu and validation check for the proposed CNFF as shown in fig 6.c. Finally, the suggested network regression value is presented in the fig 6.d.



(a) 



(c)

Fig.6. CFNN Control Design Parameters

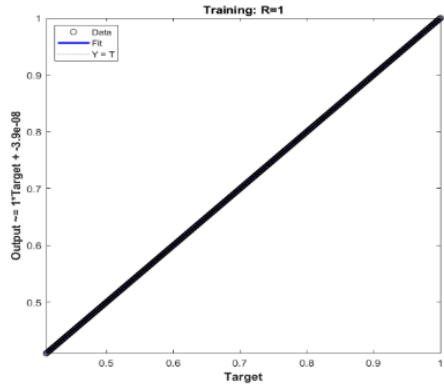

(d)

(a). Cascade Feedforward multilayer Neural Network for MPPT Algorithm (b). Analysis of best training performance of proposed CNFF (c). Analysis of gradient, Mu and Validation check for proposed CNFF (d). Analysis of regression for proposed CNFF

\section{SIMULATION RESULTS}

In this paper that the finding Maximum Power Point using different algorithms has been implemented and the simulation results are as shown below.

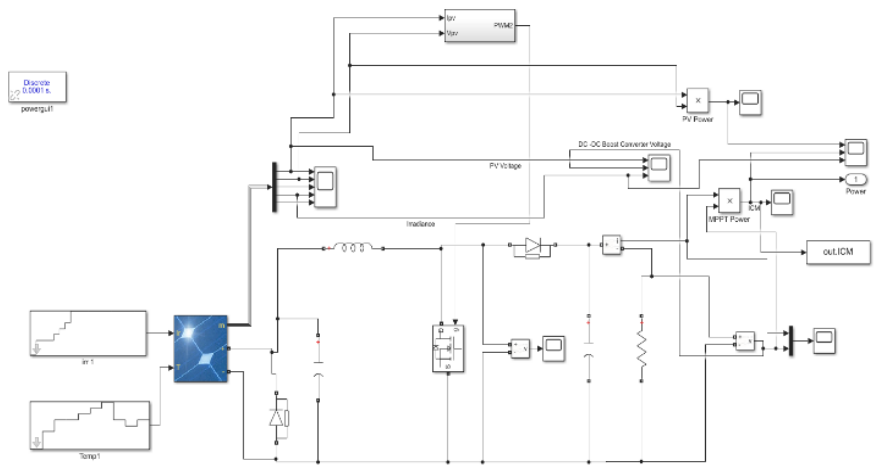

Fig.7. Simulation model $10 \mathrm{~kW}$ PV system for Various MPPT Algorithms

\section{IV.I. Fuzzy Logic (FL) Controllers Results}

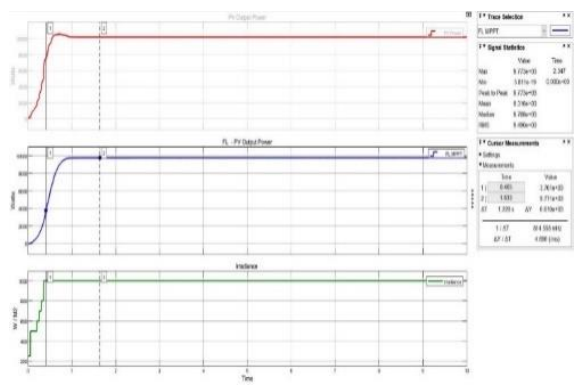

(a)

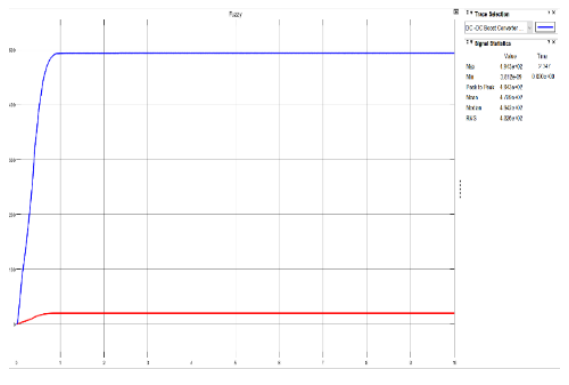

(b)



(c)

Fig. 8 Fuzzy Logic Controller Results

(a). PV output power vs MPPT PV power under various integration (b) Boost converter output voltage and current (c) PV output Voltage vs Boost converter output Voltage under various irradiance

The designed fuzzy logic Controller had implemented in MATLAB/Simulink model of $10 \mathrm{~kW}$ PV system. This simulation model has been analyzed under standard operating conditions. The simulation results are evaluated. The 
same simulation model the variable irradiance has been applied input of PV system and analyses system performance. Under various weather conditions the PV output power and MPPT output power has been recorded and plotted in fig 8.a. The boost converter voltage and current waveform are plotted under various weather conditions $493.4 \mathrm{~V}$ and 19.8 respectively in fig 8.b. Compare PV output Voltage $310 \mathrm{~V}$ and Boost converter output voltage $493.4 \mathrm{~V}$ under various irradiance as shown in fig 8.c.

\section{II Genetic Algorithm Results}

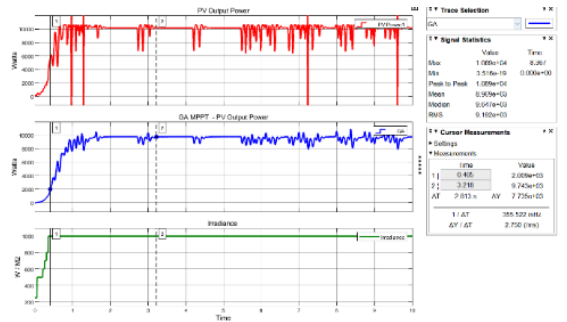

(a)

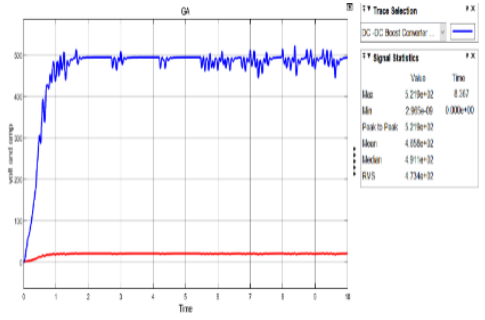

(b)

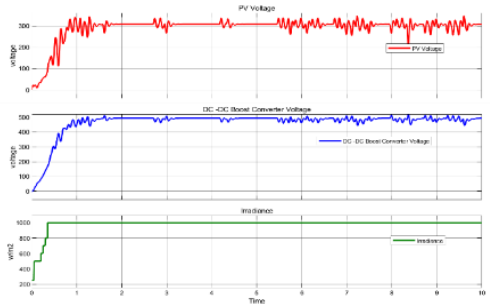

(c)

Fig.9. Genetic Algorithm Results

(a). PV output power vs MPPT PV power under various integration (b). Fig 19. Boost converter output voltage and current (c). PV output Voltage vs Boost converter output voltage under various irradiance

The designed GA Controller had implemented in MATLAB/Simulink model of $10 \mathrm{~kW}$ PV system as shown in fig 7. This simulation model has been analyzed under standard operating conditions. The simulation results are evaluated. The same simulation model the variable irradiance has been applied input of PV system and analyses system performance. Under various weather conditions the PV output power and MPPT output power $9743 \mathrm{~W}$ has been recorded and plotted in fig 9.a.. The boost converter voltage and current waveform are plotted under various weather conditions $491 \mathrm{~V}$ and 19.8 respectively in fig 9.b.. Compare PV output Voltage $310 \mathrm{~V}$ and Boost converter output voltage $491 \mathrm{~V}$ under various irradiance as shown in fig. 9.c.

\section{IV.III KGMO Algorithm Results}

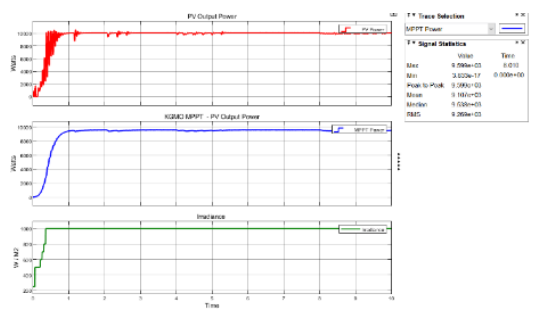

(a)

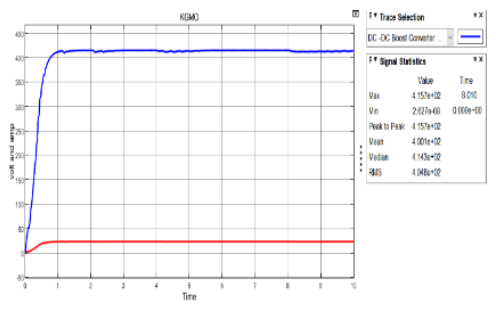

(b)

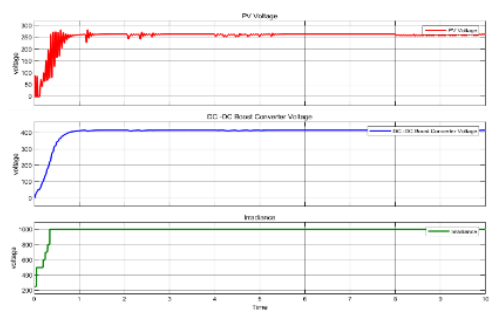

(c)

Fig.10. KGMO Algorithm Results

PV output power vs MPPT PV power under various integration (b). Boost converter output voltage and current (c). PV output Voltage vs Boost converter output voltage under various irradiance

The designed KGMO Controller had implemented in MATLAB/Simulink model of $10 \mathrm{~kW}$ PV system as shown in fig 7. This simulation model has been analyzed under standard operating conditions. The simulation results are evaluated. The same simulation model the variable irradiance has been applied input of PV system and analyses system performance. Under various weather conditions the PV output power and MPPT output power $9599 \mathrm{~W}$ has been recorded and plotted in fig 10.a. The boost converter voltage and current waveform are plotted under various weather conditions $415 \mathrm{~V}$ and 19.8 respectively in fig 10.b. Compare PV output Voltage $310 \mathrm{~V}$ and Boost converter output voltage $415 \mathrm{~V}$ under various irradiance as shown in fig 10.c. 


\section{IV.IV Cascaded Feed Forforded Neural Network Algorithm Results}

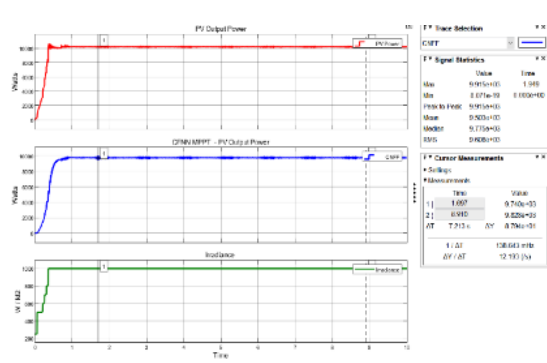

(a)

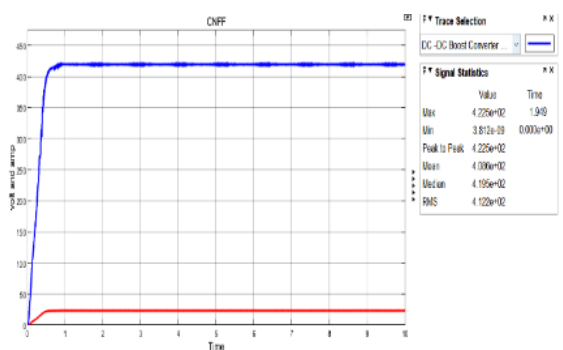

(b)

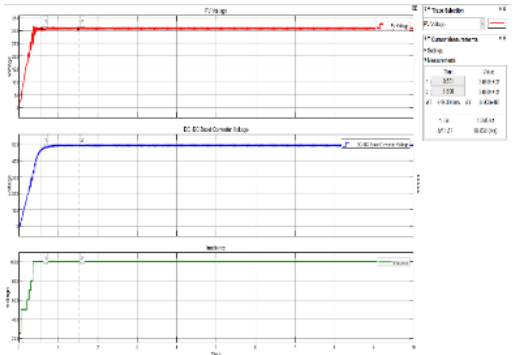

(c)

Fig.11. CFNN Algorithm Results

(a) PV output power vs MPPT PV power under various integration (b). Boost converter output voltage and current (c). $\mathrm{PV}$ output Voltage vs Boost converter output voltage under various irradiance

The designed proposed CNFF Controller had implemented in MATLAB/Simulink model of $10 \mathrm{~kW}$ PV system as shown in fig 7. This simulation model has been analyzed under standard operating conditions. The simulation results are evaluated. The same simulation model the variable irradiance has been applied input of PV system and analyses system performance. Under various weather conditions the PV output power and MPPT output power $9915 \mathrm{~W}$ has been recorded and plotted in fig 11.a. The boost converter voltage and current waveform are plotted under various weather conditions $422 \mathrm{~V}$ and 19.8 respectively in fig 11.b.

\section{HARDWARE RESULTS}

The proposed system was developed as a functional model of 10W PV system and power converter as shown in Figure 12.a. The proposed CNFF algorithm has been interfaced with Arduino mega 2560 controller, which is helpful to develop duty cycle based on input changes. Arduino's Mega 2560 interfaces directly with MATLAB using a MATLAB simulation library. Design data can be found in Table 2. The switching pulses are generated by the proposed algorithm and its run cycle will change with respect to climate change. Figure 12.b accounts for $50 \%$ of the utilization cycle generated by the proposed algorithm. Figure 12.c represents a 90\% operating cycle created by the proposed algorithm. The proposed algorithm for the duty cycle of switching pulses under different weather conditions in MATLAB is shown in Figure 12.e. The 28.20 V DC-DC converter output voltage prototype model (12 V input) as shown in Figure 12.f.

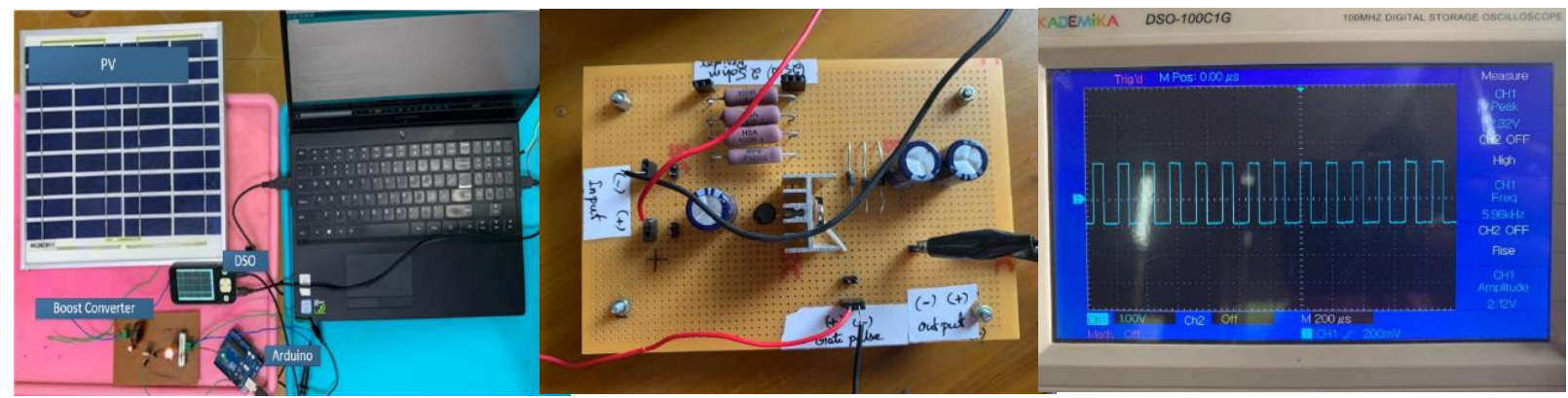




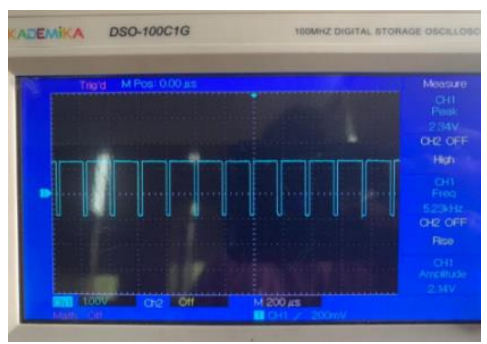

(d)



(e)



(f)

Fig. 12 Hardware Results

(a) Working model of PV MPPT system (b). DC-DC Converter Model (c). Switching signal with $50 \%$ duty cycle (d). Switching signal with $90 \%$ duty (e). Pulse generation by proposed CNFF algorithm (f). DC-DC Converter output Voltage 28.2 V (Input $12 \mathrm{~V}$ )

Table 2: PV and Boost converter parameter

\begin{tabular}{|c|c|c|}
\hline S.No & Parameter & Value \\
\hline $\mathbf{1}$ & Power & $10 \mathrm{~W}$ \\
\hline $\mathbf{2}$ & Voc & $21.20 \mathrm{~V}$ \\
\hline $\mathbf{3}$ & Isc & $0.66 \mathrm{~A}$ \\
\hline $\mathbf{4}$ & Vmax & $17.40 \mathrm{~V}$ \\
\hline $\mathbf{5}$ & Imax & $0.58 \mathrm{~A}$ \\
\hline $\mathbf{6}$ & Capacitor $\mathrm{c} 1$ & $100 \mu \mathrm{f}$ \\
\hline $\mathbf{7}$ & Capacitor $\mathrm{c} 2$ & $4700 \mu \mathrm{f}$ \\
\hline $\mathbf{8}$ & Inductor & $0.05 \mathrm{H}$ \\
\hline $\mathbf{9}$ & MOSFET & IRF540 N \\
\hline $\mathbf{1 0}$ & Resistance & $33 \Omega$ \\
\hline
\end{tabular}

Table 3 Comparison

\begin{tabular}{|c|c|c|c|}
\hline $\begin{array}{c}\text { S. } \\
\text { No. }\end{array}$ & $\begin{array}{c}\text { Name of } \\
\text { algorithm }\end{array}$ & $\begin{array}{c}\text { MPPT } \\
\text { Power }\end{array}$ & $\begin{array}{c}\text { Conversion } \\
\text { Percentage }\end{array}$ \\
\hline 1 & INC & 8405 & $84.05 \%$ \\
\hline 2 & PSO & 9312 & $93.12 \%$ \\
\hline 3 & Fuzzy & 9773 & $97.73 \%$ \\
\hline 4 & GA & 9192 & $91.92 \%$ \\
\hline 5 & KGMO & 9599 & $95.99 \%$ \\
\hline 6 & CNFF & 9915 & $99.15 \%$ \\
\hline
\end{tabular}

PV MPPT

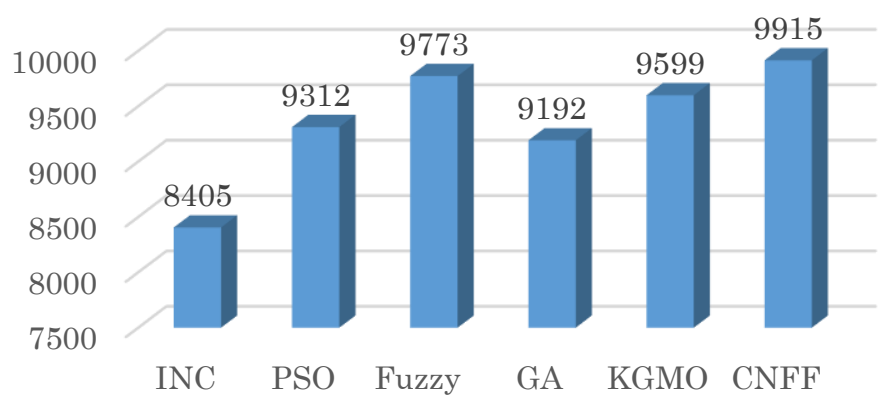

Fig 13. Comparative analysis of various MPPT techniques.

\section{CONCLUSION}

This research has focused on the maximum energy production of photovoltaic systems in a variety of meteorological conditions. The mathematical model of the photovoltaic cell has been developed and analyses its performance in different weather conditions. According to the simulation results, the MPPT algorithm was inevitable to generate the maximum power of the PV system. In this study, a number of MPPT algorithms were tested in a variety of meteorological conditions. The following algorithms were analyzed, namely 
Fuzzy, GA, KGMO and CNFF. Based on simulation results and comparative analyses, the CNFF produces better results relative to other MPPT algorithms. Comparative analyses can be found in Table 3 and Figure 13. Finally, the prototype work model was developed and checked by the proposed MPPT algorithm.

\section{REFERENCES}

1. V. Kumar and M. Singh, (2020). Derated Mode of Power Generation in PV System Using Modified Perturb and Observe MPPT Algorithm, Journal pf Modern Power Systems and Clean Energy, 1-10, doi: 10.35833/MPCE.2019.000258

2. Y Yang and H.Wen, (March 2019), Adaptive Perturb and Observe Maximum Power Point Tracking with current predictive and decoupled power control for grid-connected photovoltaic inverter, Journal of Modern Power System and Clean Energy 7(2), 422-432,; doi: 10.1007/s40565-0118-0437-x.

3. J Mishra, S Das D Kumar and M Pattnaik, (2019), Performance Comparison of P \& O and INC MPPT Algorithm for a standalone PV System, Innovations in Power and Advanced Computing Technologies (i-PACT), 1-5. Doi: 10.1109/i-PACT44901.2019.8960005

4. L Assiya, D Aziz and H Ahmed, (2020). Comparative Study of P \& O and INC MPPT algorithms for DC-DC Converter based PV System on MATLAB/SIMULINK. 2020 IEEE 2nd International Conference on Electronics, Control, Optimization and Computer Science (ICECOCS), Kenitra, Merroco doi: 10.1109/ICECOCS50124.2020.9314498

5. L Yang and Z Yunbo, (2019). A Novel Improved Variable Step Size INC MPPT Method for PV Systems. 2019 Chinese Control and Decision Conference (CCDC), Nanchang, China. 5070-5073, doi: 10.1109/CCDC.2019.8832451

6. D. Singh and H. Singh (2019). Technical Survey and Review on MPPT Techniques to attain Maxim Power of Photovoltaic System. 2019 5th International Conference on Signal Processing Computing and Control (ISPCC), Solan, India, 265-268, doi: 10.1109/ISPCC48220.2019.8988382

7. M L Azad, P K Sadhu and S Das, (2020). Comparative Study between P \& O and Incremental Conduction MPPT Techniqus - A Review. 2020 International Conference on Intelligent Engineering and Management (ICIEM), Landon, UK, 217-222, doi: 10.1109/ICIEM48762.2020.9160316

8. G Anand Kumar. M Venkatesh Kumar and P Shankar (2013). Intelligent Controller based MPPT Method for Photovoltaic Power System. International Conference on Human Computer Interactions (ICHCI). Chennai, India doi: 10.1109/ICHCI-IEEE.2013.6887790.

9. D Haji and N Genc (2018), Fuzzy and P \& O based MPPT Controllers under different Conditions. 7th International Conference oon Renewable Energy Research and Applications (ICRERA) Paris, France, 649-655, doi: 10.1109/ICRERA.2018.8566943.

10. M L Shah, A Dhaneria, P S Modi, H Khambhadia and K K D, (2020). Fuzzy Logic MPPT for Grid Tie Solar Inverter. IEEE International Conference for Innovation in Technology (INOCON), Bangalore, India, doi: 10.1109/INOCON50539.2020.9298323.

11. M R Javed, A Waleed, U S Virk and S Z Ul Hassan (2020), Comparison of the Adaptive Neural-Fuzzy Interface System (ANFIS) based Solar Maximum Power Point Tracking (MPPT) with other Solar MPPT Methods. IEEE 23rd International Multitopic Conference (INMIC) Bahawalpur, Pakistan, doi: 10.1109/INMIC50486.2020.9318178

12. J I Corcau, and L Dinca (2019). Modelling and Analysis of Fuzzy type MPPT Algorithm. 2019 International Conference on Electrical Drives and Power Electronics (EDPE), The High Tatras, Slovakia, 230-234, doi: 10.1109/EDPE.2019.8883925

13. D Reddy and S Ramaswamy (2017), A Fuzzy logic MPPT Controller based three phase grid-tied Solar PV System with improved CPI Voltage. 2017 Innovations in Power and Advanced Computing Technologies (i-Pact), Vellore, India, doi: 10.1109/IPACT.2017.8244953

14. S Paul and J Thomas, (2014). Comparison of MPPT using GA optimized ANN employing PI Controller for Solar PV system with MPPT using Incremental Conductance, 2014 International Conference on Power Signal Control 
and Computations (EPSCICON), Thrissur, India doi: 10.1109/EPSCICON.2014.6887518

15. Badis, M N Mansouri and M H Boujmil (2017). A Genetic algorithm Optimized MPPT Controller for a PV system with DC-DC boost Converter, 2017 Internationa Conference on Engineering \& MIS (ICEMIS) Monastri, Tunisia, doi: 10.1109/ICEMIS.2017.8273010

16. L Zaghba et al (2019). A Genetic Algorithm based improved P \& O - PI MPPT Controller for stationary and Tracking Grid Connected Photovoltaic System, 2019 7th International Renewable and Sustainable Energy Conference (IRSEC), Agadir, Morocco, 2019,1-6

17. S Paul, (2013), Comparison of MPPT using GA Optimized ANN employed PI Controller with GA Optimized ANN employing fuzzy controller for PV System. IET 4th International Conference on Sustainable Energy and Intelligent Systems (SEISCON) Chennai, 2013, 266-271, doi: 10.1049/ic.2013.0324

18. R Khanaki, M A M Radzi, and M H Marhaban, (2013), Comparison of ANN and P \& O MPPT Methods for PV Applications under changing solar irradiance, 2013 IEEE Conference on Clean Energy and Technology (CEAT), Langkawi, Malasiya, 2013, 287-292, doi: 10.1109/CEAT.2013.6775642

19. H Elaissaoui, M Zerouali, A E Ougli and B Thidaf, (2020). MPPT Algorithm based on Fuzzy Logic and Artificial Neural Network (ANN) for a Hybrid Solar/Wind Power Generation System, 2020, 4th International Conference on Intelligent Computing in Data Sciences (ICDS), FEZ, Morocco, 2020, doi: 10.1109/ICDS50568.2020.9268747

20. M S Bouakkaz A Boukadoum, O Boudebbouz, A Bouraiou, N boutasseta and I Attoui (2020), ANN based MPPT Algorithm Design using Real Operating Climatic Condition, 2020 2nd International Conference on Mathematics and Information Technology (ICMIT), Adrar, Algeria, 2020, 159-163, doi: 10.1109/ICMIT47780.2020.9046972

21. L Bouselham, M Hajji, B Hajji and H Bouali, (2016). A MPPT based ANN Controller applied to PV Pumping System, Internation Renewable and Sustainable Energy Conference (IRSEC), Marrakech, Morocco, 2016, 86-92, doi: 10.1109/IRSEC.2016.7983918

22. S Messalti, A G Harrag and A E Loukriz, (2015), A New Neural Networks MPPT Controller for PV Systems, IREC2015, the sixth International Renewable Energy Congress, Sousse, Tunisia, 2015, doi: 10.1109/IREC.2015.7110907

23. Arulmozhiyal and K. R Baskaran, "Implementation of a Fuzzy PI Controller for Speed Control of Induction Motors Using FPGA," Journal of Power Electronics, vol. 10, pp. 65-71, 2010.

24. D. Zhang, et al., "Common Mode Circulating Current Control of Interleaved Three-Phase Two-Level VoltageSource Converters with Discontinuous Space-Vector Modulation," 2009 IEEE Energy Conversion Congress and Exposition, Vols 1-6, pp. 3906-3912, 2009.

25. Z. Yinhai, et al., "A Novel SVPWM Modulation Scheme," in Applied Power Electronics Conference and Exposition, 2009. APEC 2009. Twenty-Fourth Annual IEEE, 2009, pp. 128-131. 